International Journal of Engineering \& Technology, $7(4.5)(2018) 696-699$
SPC
Snternational Journal of Engineering \& Technology
Website $\frac{w w w . s c i e n c e p u b c o . c o m / i n d e x . p h p / I J E T}{2}$
Research paper

\title{
A review of recent developments in geopolymer concrete
}

\author{
A. Chithambar Ganesh ${ }^{1}$, Dr. M. Muthukannan ${ }^{1}$ \\ ${ }^{1}$ Department of Civil Engineering, Kalasalingam University \\ *Corresponding author E-mail: chithambarmailid@gmail.com
}

\begin{abstract}
Geopolymer concrete is proved to have high strength, lesser shrinkage, resistance against reinforcement corrosion, acid and sulphate resistance, freeze-thaw resistance, fire resistance and resistance to alkali-aggregate reaction. There are many parameters which influence the strength characteristics of Geopolymer Concrete. They are types and fineness of Source alumino silicate material used, concentration and type of alkaline activators used, curing temperature and curing time, utilization of M-sand etc. High performance characteristics could be achieved through the correct choice of these parameters. This review paper focuses on the influence of different variables on the properties of geopolymer concrete and the progress in the field of geopolymer concrete. Consequently many research papers pertaining to the geopolymer have been reviewed in this state of art paper.
\end{abstract}

Keywords: Use about five key words or phrases in alphabetical order, Separated by Semicolon.

\section{Introduction}

The demand of concrete is increasing day by day for satisfying the need of development of infrastructure facilities. It is well established fact that the production of OPC not only consumes significant amount of natural resources and energy but also releases substantial quantity of carbon dioxide to the atmosphere. Therefore, it is essential to find alternatives to make the concrete environment friendly (1). Geopolymer is a recent invention in the world of concrete in which cement is totally replaced by pozzolanic material that is rich in silica and alumina like fly ash and activated by alkaline liquids to act as a binder in the concrete (2).

Two types of materials are required to make a geopolymer. One is the source material containing alumina and silica and other is an alkali that activates the polymerization reaction. The source materials (alumino-silicate) may be natural minerals, such as kaolinite, calcined kaolinite and clays. Alternatively, industry waste products such as fly ash, slag, red mud, rice-husk ash and silica fume may be used as source material for the synthesis of geopolymers(3). The source material should be amorphous and degree of polymerization mainly depends on the degree of amorphosity and fineness of alumino silicate materials. The alkali component used as an activator is a compound from the elements of the first group in the periodic table (4). The common activators are $\mathrm{NaOH}$, $\mathrm{Na} 2 \mathrm{SO} 4$, water glass, $\mathrm{Na} 2 \mathrm{CO} 3, \mathrm{~K} 2 \mathrm{CO} 3, \mathrm{KOH}, \mathrm{K} 2 \mathrm{SO} 4$ or a little amount of cement clinker and complex alkali component. For the preparation of the alkali solution a single alkali type or a mixture of different alkalis can be used.

Curing can be done either at room temperature or at elevated temperatures. During the curing process, the geopolymer concrete experiences polymerization process. Due to the increase in temperature, polymerization become more rapid and the concrete gain $70 \%$ of its strength within short period of time (5). The addition of fibers improves the ductile property of Geopolymer Concrete and also improves the post cracking behavior of Geopolymer Concrete (6).

\section{Review of various parameters}

Review of various papers pertaining to the effect of fineness of source materials, concentration and ratio of alkali activators used, utilization of $\mathrm{m}$-sand, method of curing and addition of fibers are discussed below

\subsection{Effect of fineness and type of binding materials}

Muhammad N.S. Hadi, Nabeel A. Farhan, M. Neaz Sheikh(7) studied about the design of optimum mix proportions for geopolymer concrete using ground granulated blast furnace slag (GGBFS). Then GGBFS was partly replaced by flyash, metakaolin and silica fume in various proportions. Ambient Curing was performed for the specimens. Results showed that the decrease in calcium content in the alumino silicate source material delays the polymerization reaction and delays the formation of an amorphously structured $\mathrm{Ca}-\mathrm{Al}-\mathrm{Si}$ gel. It is also deduced that decrease in calcium content reduced the compressive strength.

ParthaSarathi Deb and Prabir Kumar Sarker(8) tried to develop a flyash based geopolymer concrete by curing under ambient temperature using partial replacement of flyash with GGBS. In this study Flyash was replaced in proportions of $10 \%$ and $20 \%$ with GGBS. Alkali flyash ratio was kept as 0.35 . Compresive strength test, Drying Shrinkage test, Sorptivity test and Volume of permeable voids test were performed in this study. It was observed that $20 \%$ of partial replacement with GGBS yielded better compressive strength. Addition of GGBS decreased the sorptivity test results, driying shrinkage test and volume of permeable voids test.

Sundeep Inti, Megha Sharma and Dr.Vivek Tandon(9) investigated the utilization of Ground Granulated Blast Furnace Slag (GGBS) and Rice Husk Ash (RHA) to replace fly ash in Geopolymer concrete. Compressive strength test and micro structural studies were carried out in this study. Results indicated that complete replacement of Fly ash in geopolymer concrete with RHA and GGBS is not feasible. Results showed that by $50 \%$ partial 
replacement of flyash using GGBS higher compressive strength. Similar strength could be achieved using 5-10 \% RHA.

Rasoul Shadnia and Lianyang Zhang, (10) posed a paper on the experimental study of Geopolymer Synthesized with Class F Fly Ash and Low-Calcium Slag. Experimental work involved the production of geopolymer concrete using class F-Flyash and low calcium Slag at different proportions. Concentration of Sodium hydroxide was also varied from 7.5 to $15 \mathrm{M}$. Curing time and Curing temperature also were varied and their effects were studied in this paper. Compressive strength test and micro structural investigations were carried out. Results showed that addition of slag increased the compressive strength and unit weight as it processes more specific gravity.

P. Chindaprasirt, T. Chareerat, S. Hatanaka and T. Cao (11) propounded a paper about the synthesis of High-Strength Geopolymer Using Fine High-Calcium Fly Ash. This paper dealt with the experimental study on the effect of fineness of flyash on the properties of geopolymer concrete. Combination of Sodium silicate and Sodium hydroxide of $10 \mathrm{M}$ solution was used as the alkali activator. The results indicated that the setting time of paste decreased with an increase in fly-ash fineness but compressive strength increased with increase in fineness.

Pattanapong Topark-Ngarm, PrinyaChindaprasirt and VanchaiSata (12) posed a paper on the study of setting time, strength, and bond of High-Calcium flyash based Geopolymer Concrete. Alkaline liquid to fly ash ratio was kept as 0.5 . Combination of Sodium silicate and Sodium hydroxide solution was used as the alkali activator. The results indicated that high calcium content in flyash decreased the setting time of geopolymer concrete. Results also showed that high compressive strength and bond between bar and the concrete increased with the use of high calcium flyash.

P. Nath, P. K. Sarker (13) published a paper on Geopolymer concrete under ambient curing condition. In this study, Class F Flyash was used to produce geopolymer concrete. Combination of Sodium silicate and Sodium hydroxide solution was used as alkali activator solution. The specimens were ambient cured before testing. GGBS was added to replace flyash in proportions up to $30 \%$ and the properties such as setting times of geopolymer pastes, workability of fresh concrete and compressive strength of hardened concrete were investigated. It was inferred from the results that the blend of fly ash and slag improved the mechanical properties of geopolymer concrete cured at ambient condition. Results showed that addition of slag up to $30 \%$ of the total binder yielded compressive strength up to $55 \mathrm{MPa}$ at 28 days however setting time reduced rapidly with the increasing amount of slag in the mixture.

Du Haiyan, Yang Lina, Gao Wanqi, Liu Jiachen(14) have investigated the properties of geopolymer concrete synthesized from two types of fly ash fly ashes produced in wet bottom and dry bottom boilers. Combination of Sodium hydroxide and sodium silicate solution was used as alkali activator solution. Compressive strength and micro structural investigations were carried out in this study. The results revealed that the geopolymer produced with wet bottom boiler fly ash hardened quickly, and had higher earlyage strength and lower shrinkage than the geopolymer produced with dry bottom boiler fly ash. The compressive strength of the two geopolymers made from wet bottom boiler fly ash and dry bottom boiler fly was almost the same after 28 days. Dry bottom boiler flyash specimens had more shrinkage compared with the wet bottom boiler flyash specimens.

\subsection{Effect of the alkali activators}

Pattanapong Topark-Ngarm, PrinyaChindaprasirt and VanchaiSata(12) investigated Setting time, strength and bond of highcalcium fly ash geopolymer concrete. In this study, alkaline liquid to fly ash ratio was kept as 0.5 . Sodium silicate to sodium hydroxide ratios was kept as 1.0 and 2.0. Concentration of Sodium hydroxide solution was varied in three proportions such as $10 \mathrm{M}, 15$ $\mathrm{M}$, and $20 \mathrm{M}$. The two curing regimes such as heat curing at $60^{\circ} \mathrm{C}$ for $24 \mathrm{hrs}$ and room temperature curing at $23^{\circ} \mathrm{C}$ were used. Re- sults revealed that strength and the elastic modulus of geopolymer concrete increases as the molarity increases.

GauravNagalia, Yeonho Park (15) proposed a paper on Compressive Strength and Micro structural Properties of Fly Ash-Based Geopolymer Concrete. The role of alkali hydroxide and its concentration on the development of compressive strength was investigated in this study. In this study, geopolymers made by mixing Class $\mathrm{C}(9.42 \% \mathrm{CaO})$ and Class F-fly ash $(1.29 \% \mathrm{CaO})$ were investigated with different alkaline solutions such as $\mathrm{NaOH}, \mathrm{KOH}$, $\mathrm{Ba}(\mathrm{OH})_{2}$, and $\mathrm{LiOH}$. Micro structural investigations using X-ray diffraction (XRD) and scanning electron microscopy (SEM) were also carried out. Result showed that $\mathrm{NaOH}$ ie) sodium hydroxide was the only one solution to produce high activation. The Molarity of sodium hydroxide was varied from 8,12 and 14M. Results revealed that the compressive strength increased with the increase in molarity.

Rashidah Mohamed Hamidi, Zakaria Man and KhairunAziziAzizli (16) propounded a paper on the effect of Concentration of $\mathrm{NaOH}$ on the Properties of Fly Ash Based Geopolymer. Combination of Sodium silicate and Sodium hydroxide solution was used an activator solution. Curing was done at $60^{\circ} \mathrm{C}$ for 1 day. The influence of $\mathrm{NaOH}$ concentration in the range of $4 \mathrm{M}$ to $18 \mathrm{M}$ was systematically studied using Fourier Transform Infrared Spectroscopy (FTIR) for structural elucidation. Scanning Electron Microscope (SEM) analysis was carried out to observe the morphology. Flexural strength of the specimens was also performed. Results revealed that optimum molarity was $12 \mathrm{M}$ with good performance in all the tests.

V. Supraja and M. Kanta Rao (17) studied the effect of molarity in GGBS based geopolymer concrete. Alkaline liquid to GGBS ratio was kept as 0.30.Combination of Sodium silicate and Sodium hydroxide solution was used a activator solution. Molarity of sodium hydroxide was varied from $3 \mathrm{M}$ to $9 \mathrm{M}$. The two curing regimes such as heat curing at $60^{\circ} \mathrm{C}$ for $24 \mathrm{hrs}$ and curing by sun light were adopted. Compressive strength test was carried out for the specimens of various molarities and different curing conditions. Results concluded that strength of GPC increased with the increase in molarity of sodium hydroxide. This was observed under both the curing condition.

K.Surya Teja, M.Tagore Sunil Sai, Y.Himath Kumar (18) presented a paper on the experimental study on the properties of Geopolymer concrete with GGBS as a Binder. Combination of Sodium silicate solution and Sodium hydroxide solution was used as an activator solution. Molarity of the solution was varied as $8 \mathrm{M}$ and $10 \mathrm{M}$ and their effect was investigated in this paper by finding the compressive strength and flexural strength. Results revealed that compressive strength increased with increase in molarity. Results also showed that increase in flexural strength was not significant. A.Iftiqar Ahmed, Dr. S. Siddiraju(19) propounded a paper on the topic strength properties on Flyash based Geopolymer Concrete with admixtures. Flyash was used as the alumino silicate material for the synthesis of geopolymer concrete. The aggregate volume is assumed to be $65 \%$ of the total volume. Combination of Sodium silicate and Sodium hydroxide solution was used as an activator solution. In this investigation the molarities of Sodium hydroxide was varied as $8 \mathrm{M}, 12 \mathrm{M}$, and $16 \mathrm{M}$. Two regimes of curing such as curing by oven and curing by sunlight were adopted. Results showed that under both types of curing, compressive strength increased with the increase in the molarity of sodium hydroxide.

Prakash R. Voraa, Urmil V. Dave(20) posed a paper on Parametric Studies on Compressive Strength of Geopolymer Concrete. This paper described the experimental work conducted to evaluate the effect of various parameters affecting the compressive strength. Low calcium Class F Flyash was used as the alumino silicate material. Two concrete mixes Mix-1 and Mix-2 with the alkaline liquid to fly ash ratio 0.35 and 0.4 were casted. The ratio of Sodium silicate and sodium hydroxide to be used as activator solution was also varied. Molarity of Sodium hydroxide solution was varied as $8 \mathrm{M}, 10 \mathrm{M}, 12 \mathrm{M}$ and $14 \mathrm{M}$. Results revealed that ratio of alkaline solution to flyash did not have more influence on the 
strength. Also the compressive strength increased with the increase in the concentration of Sodium hydroxide.

Subhash V. Patankar, Yuwaraj M. Ghuga and Sanjay S. Jamkar (21) investigated the effect of Concentration of Sodium Hydroxide on Fly Ash-Based geopolymer concrete. In this experimental study the effect of molarity on the compressive strength of geopolymer concrete was investigated for various solution to flyash ratio as $0.35,0.40$, and 0.45 . This study was conducted for various curing temperatures such as $40,60,90$, and $120^{\circ} \mathrm{C}$ each for a heating period of 24 hours. Test results shown that the workability and compressive strength both increased with increase in concentration of sodium hydroxide solution for all solution-to-fly ash ratios.

\subsection{Effect of M-sand as fine aggregate}

Mohamed Aquib Javeed, VeerendraKumar.M, Dr. H.Narendra(22) published a paper on Studies on Mix Design of Sustainable GeoPolymer Concrete. In this study combination of manufactured sand and pond ash was used to replace conventional natural river sand. Blend of flyash and grounded granulated blast furnace slag was used as alumino silicate materials. Combination of Sodium silicate and Sodium hydroxide solution was used as alkali activator solution. Ambient curing was adopted in this study. ConplastSP-430 grade super plasticizer was used as super plasticizer. The mix design was based on Rangan method for M30 grade of concrete. The alkaline to binder ratio were taken as 0.55 and molarity of sodium hydroxide was taken as $14 \mathrm{M}$. The compression strength for hardened concrete and compaction factor for fresh concrete were evaluated. As a result, about $60 \%$ of M-sand and $40 \%$ of pond ash as sand replacement was found to be the optimum amount in order to get a favorable strength. Results showed that use of GGBS about $20 \%$ by mass of fly ash in a geo-polymer concrete, increased the strength of concrete.

Pradeepkumar, Prabhakar (23) posed a paper on Study of Strength Development of Geopolymer Concrete using M-Sand as Fine Aggregate. Fly ash was used as the alumino silicate source material. Combination of Sodium silicate and Sodium hydroxide solution as used as the alkali activator solution. In this paper, material properties of flyash, M-sand and mechanical properties of geopolymer concrete were conducted. Results showed that the replacement of M-sand reduced the hydration and also showed increase in the value of compressive strength for $5 \mathrm{M}$ and $10 \mathrm{M}$ by $4.08 \%$ and $9.51 \%$ also showed increase in the value of Split tensile strength for $5 \mathrm{M}$ and $10 \mathrm{M}$ by $9.2 \%$ and $4.5 \%$ respectively.

K. Arulpriya (24) proffered a paper on Strength and Durability studies of M-Sand and Fly ash based geopolymer concrete. In this study low-calcium fly ash based geopolymer was used as the binder. Specimens were casted for various sodium silicate to sodium hydroxide ratio from 0.67 to 1.00 and various molarities from $10 \mathrm{M}$ to $20 \mathrm{M}$. Compressive strength test, tensile strength test, impact strength test, acid resistance test, sulphate resistance test and sorptivity test were conducted. Results showed that the M-Sand based geopolymer concrete shows good workability compared to concrete made with river sand. The compressive strength was $23.78 \%$ higher than normal concrete. The results from durability tests showed that Geopolymer concrete using M-sand had excellent resistance to sulphate attack.

S. Nagajothi and S. Elavenil (25) used low calcium fly ash as an inorganic non metallic alternative material for cement and evaluated the performance of manufactured sand as an alternative for river sand. Combination of Sodium silicate and 16M Sodium hydroxide solution was used as the alkali activator solution. Specimens were oven cured at $60^{\circ} \mathrm{C}$ for 24 days and tested after 7 days and 28 days. Compressive strength and split tensile strength were conducted. River sand was replaced with M-sand in $20 \%, 40 \%$, $60 \%, 80 \%$ and $100 \%$. The percentage replacement of M-sand in Geopolymer concrete was assessed from the results and found to yield fair strength with the utilization of M-sand.

Maneeshkumar C S,Manimaran G, Prasanth S(26) conducted a study on the strength assessment of geopolymer concrete using Msand. Blend of flyash and GGBS was used as the binder material.
Combination of Sodium silicate and 10M Sodium hydroxide solution was used as alkali activator solution. Ratio of Alkali solution to binder content was kept as 0.4. Compressive strength test, Split tensile strength test and Flexural strength test was performed after 7, 14 and 28 days. Total aggregate was taken as $70 \%$ of total volume. Quarry dust was used as M-sand in $50 \%$ and $100 \%$. Results showed that the Quarry dust can be partly used but cannot replace completely.

\subsection{Effect of curing type and curing period}

Prakash R. Voraa, Urmil V. Dave (20) posed a paper on Parametric Studies on Compressive Strength of Geopolymer Concrete. This paper described the experimental work conducted to evaluate the effect of various parameters affecting the compressive strength. Low calcium Class F Flyash was used as the alumino silicate material. Two concrete mixes Mix-1 and Mix-2 with the alkaline liquid to fly ash ratio 0.35 and 0.4 were casted. The ratio of Sodium silicate and sodium hydroxide to be used as activator solution was also varied. Molarity of Sodium hydroxide solution was varied as $8 \mathrm{M}, 10 \mathrm{M}, 12 \mathrm{M}$ and $14 \mathrm{M}$. The test specimens were cured at $75^{\circ} \mathrm{C}$ for 24 hours and 48 hours in an oven. Results showed that the compressive strength of the geopolymers concrete increased with increase in the curing time. Also there was a considerable increase in the compressive strength of Geopolymer concrete when the curing temperature was in the range $60^{\circ} \mathrm{C}$ to $90^{\circ} \mathrm{C}$ and up to 24 hours of curing time.

Subhash V. Patankar, Yuwaraj M. Ghuga and Sanjay S. Jamkar(27) investigated the effect of Degree of Heat Curing on Fly Ash-Based geopolymer concrete. Alkali solution to fly ash ratio was kept as $0.35,0.40$, and 0.45 . Combination of Sodium silicate solution and Sodium hydroxide solution of various molarities was used as alkali activator solution. In this study the effect of heat curing was studied for various temperatures such as $40^{\circ} \mathrm{C}$, $60^{\circ} \mathrm{C}, 90^{\circ} \mathrm{C}$, and $120^{\circ} \mathrm{C}$ each for a heating period of 24 hours and tested for compressive strength at the age of 3 days. Results showed that increase in degree of heating accelerated the rate of strength gain and was significant till $60^{\circ} \mathrm{C}$.

V. Supraja and M. Kanta Rao (17) studied about the influence of curing method in the strength of Geopolymer Concrete. In this work, Alkaline liquid to GGBS ratio was kept as 0.30 . Molarity of Sodium hydroxide was varied from $3 \mathrm{M}, 5 \mathrm{M}, 7 \mathrm{M}$, and $9 \mathrm{M}$. Cubes were casted to calculate the compressive strength at 3 and 7 days. Two regimes of curing were carried out by exposure to sunlight for a batch and Oven curing at $50^{\circ} \mathrm{C}$ was done for another batch. Results showed that oven dried curing have no significant increase in the strength after 3 days of oven curing but rate of gain of strength was more than curing by exposure to sunlight.

A.Iftiqar Ahmed (19) investigated the influence of curing method in affecting the compressive strength of geo- polymer concrete for the mixes of varying molarities of Sodium hydroxide in the range of $8 \mathrm{M}, 12 \mathrm{M}$, and $16 \mathrm{M}$. Compressive strength test was evaluated through the cubes. Curing was done by hot air oven for one batch and curing by direct sun light for another batch. Oven cured specimens yielded more the compressive strength but sunlight curing was conveniently good for practical conditions.

\section{Conclusion- summary}

Based on the above discussions geopolymer could be effectively used as a construction material by optimizing the various factors that control their performance. Alumino silicate source material with less calcium content delays the setting time of geopolymer concrete and retards the rate of gain of strength. With the utilization of high calcium content flyash the polymerization reaction could be accelerated thereby reducing the settling time. Utilization of High calcium flyash also leads to increase in the compressive strength. GGBS could be incorporated with flyash for better gain of strength under ambient curing. This is also found to yield better compressive strength than flyash based geopolymer concrete. 
Addition of GGBS also provides better durability properties and increases the unit weight o geopolymer concrete. It is also possible to obtain fair strength by using partial replacement of flyash with rice husk ash in very small proportions of about $10 \%$. In general, increase in the fineness of binder material increases the strength of Geopolymer. Out of all the available alkali activators, combination of Sodium silicate and Sodium hydroxide solution proved to produce fair activation of polymerization process. Also with the increase in the concentration of Sodium hydroxide there is an increase in the compressive strength. This Molarity increase also leads to increase in brittle nature of the concrete. M-sand can be utilized to produce sustainable Geopolymer concrete and this also increases the compressive strength if the M-sand is finer. Ambient curing is possible in Geopolymer concrete with the addition GGBS with flyash. However oven curing can be done at $60^{\circ} \mathrm{C}$ for 24 hours for earlier strength gain.

\section{References}

[1] V.M.,Malhotra, "Introduction to Sustainable Development and Concrete technology", ACI Concrete Journal, pp.1147-1165.

[2] D. Hardjito and B. V. Rangan "Development and Properties of Low-Calcium Fly Ash-Based Geopolymer Concrete", Research Report GC 1, Curtin University of Technology, Perth, Australia, 2005.

[3] J. Davidovits, (1988b). Geopolymer Chemistry and Properties.

[4] J. Davidovits, (1994b). Properties of Geopolymer Cements.

[5] J. Davidovits, (1991). Geopolymers: Inorganic Polymeric New Materials. Journal of Thermal Analysis.

[6] J.W. Giancaspro, C.G. Papakonstantinou, P.N. Balaguru, "Flexural Response of Inorganic Hybrid Composites with E-Glass and Carbon Fibers", Journal of Engineering Materials and Technology, 2010 .

[7] N.S. Muhammad Hadi, A. Nabeel Farhan, M. Neaz Sheikh, "Design of geopolymer concrete with GGBFS at ambient curing condition using Taguchi method", Construction and Building Materials, 140 424-431.

[8] ParthaSarathi Deb and Prabir Kumar Sarker, "Properties Of Fly Ash And Slag Blended Geopolymer Concrete Cured At Ambient Temperature", New Developments in Structural Engineering and Construction, ISBN-978-981-07-5354-2.

[9] Sundeep Inti, Megha Sharma and Dr.Vivek Tandon, "Ground Granulated Blast Furnace Slag (GGBS) and Rice Husk Ash (RHA) Uses in the Production of Geopolymer Concrete", Geo-Chicago 2016, ASCE Journal, 2016.

[10] Rasoul Shadnia and Lianyang Zhang, "Experimental Study of Geopolymer Synthesized with Class F Fly Ash and Low-Calcium Slag", Journal of Materials in Civil Engineering, Volume 29, Issue 10 , ASCE Journal, October 2017.

[11] P. Chindaprasirt, T. Chareerat, S. Hatanaka and T. Cao, "HighStrength Geopolymer Using Fine High-Calcium Fly Ash”, Journal of Materials in Civil Engineering, Volume 23, Issue 3, ASCE Journal, March 2011.

[12] Pattanapong Topark-Ngarm, PrinyaChindaprasirt and VanchaiSata, "Setting Time, Strength, and Bond of High-Calcium Fly Ash Geopolymer Concrete", Journal of Materials in Civil Engineering, Voulme 27, Issue 7, ASCE Journal, July 2015.

[13] P Nath, PK Sarker, "Effect of GGBFS on setting, workability and early strength properties of fly ash geopolymer concrete cured in ambient condition", Construction and Building Materials, Volume 66, Elsevier, September 2014.

[14] Du Haiyan, Yang Lina, Gao Wanqi, Liu Jiachen, "Effects of characteristics of fly ash on the properties of geopolymer", Transactions of Tianjin University,Springer, Volume 22, Issue 3, June 2016, pp 261-267.

[15] GauravNagalia, Yeonho Park,"Compressive Strength and Micro structural Properties of Fly Ash-Based Geopolymer Concrete", Journal of Materials in Civil Engineering, ASCE Journal, Voulme 28, Issue 12, December 2016.

[16] Rashidah Mohamed Hamidi, Zakaria Man and KhairunAzizi,"Concentration of $\mathrm{NaOH}$ and the Effect on the Properties of Fly Ash Based Geopolymer", Procedia Engineering, 148 (2016), Elsevier, pp $189-193$.

[17] V. Supraja and M. Kanta Rao, "Experimental study on GeoPolymer concrete incorporating GGBS", International Journal of
Electronics, Communication \& Soft Computing Science and Engineering ISSN: 2277-9477, Volume 2, Issue 2.

[18] K.Surya Teja , M.Tagore Sunil Sai , Y.Himath Kumar, "Experimental Studies on Properties of Geo-Polymer Concrete with GGBS as a Binder, International Journal of Research in Engineering and Technology, eISSN: 2319-1163, Volume 5, Issue 4,April 2016.

[19] A.Iftiqar Ahmed, Dr. S. Siddiraju, "Strength Properties on Fly Ash Based Geo Polymer Concrete with Admixtures", International Journal of Civil Engineering and Technology (IJCIET) Volume 7, Issue 3, May-June 2016.

[20] R. Prakash, Voraa, V. Urmil, Dave, "Parametric Studies on Compressive Strength of Geopolymer Concrete", Procedia Engineering, Elsevier, 2013, pp-210-219.

[21] V. Subhash, Patankar, M. Yuwaraj, Ghuga and S. Sanjay, Jamkar, "Effect of sodium hydroxide on flow and strength of fly ash based geopolymer mortar", Indian Journal of Materials Science, Volume 2014, April 2012.

[22] Mohamed Aquib Javeed, M. VeerendraKumar, Dr. H.Narendra, "Studies on Mix Design of Sustainable Geo-Polymer Concrete", International Journal of Innovative Research in Engineering \& Management (IJIREM) ISSN: 2350-0557, Volume-2, Issue-4, July 2015

[23] B. Pradeepkumar, K. Prabhakar, S. Praveen Raj, B. Pravin kumar, M.Srihari.M, "Study of Strength Development of Geopolymer Concrete using MSand as Fine Aggregate", International Journal of Engineering Science and Computing, April 2017.

[24] K.Arul priya, "Strength and Durability Studies of M-Sand and Fly Ash Based Geopolymer Concrete", International Journal of Trend in Research and Development, Volume 3(3), ISSN: 2394-9333, June 2016 .

[25] S. Nagajothi and S. Elavenil, "Strength Assessment of Geopolymer Concrete Using M-Sand", International Journal of Chemical Science, ISSN 0972-768X, pp- 115-126.

[26] C.S. Maneeshkumar, G. Manimaran, S. Prasanth, “An Experimental Investigation on GGBS and Flyash Based Geopolymer Concrete with Replacement of Sand by Quarry Dust", International Journal of Engineering Research and Applications, ISSN: 2248-9622, Volume. 5, Issue 5, (Part -1) May 2015, pp.91-95.

[27] V. Subhash, Patankar, M. Yuwaraj, Ghuga and Sanjay S. Jamkar, "Effect of Concentration of Sodium Hydroxide and Degree of Heat Curing on Fly Ash-Based Geopolymer Mortar", Indian Journal of Materials Science, Volume 2014. 